\title{
An investigation of proton conductivity of binary matrices sulfonated polysulfone/polyvinyltriazole after doping with inorganic acids
}

\author{
SERKAN SEVINÇ, SEVIM ÜNÜGÜR ÇELIK* and AYHAN BOZKURT \\ Department of Chemistry, Fatih University, 34500 Büyükçekmece-Istanbul, Turkey
}

MS received 11 April 2013; revised 12 July 2013

\begin{abstract}
As anhydrous proton conductive membranes, sulfonated polysulfone (SPSU) and polyvinyl triazole were studied as binary matrices. The sulfonation of polysulfone was performed with trimethylsilylchlorosulfonate and high degree of sulfonation $(140 \%)$ was obtained. Ion exchange capacity of SPSU was determined as $3.05 \mathrm{mmol}^{-1} / \mathrm{g}$. The polymer electrolyte membranes were prepared by blending of sulfonated polysulfone with polyvinyl triazole and phosphoric acid. Fourier transform infrared spectroscopy confirmed the sulfonation of the polysulfone and the ionic interaction between sulfonic acid and triazole units. Thermogravimetric analysis showed that the polymer electrolyte membranes are thermally stable up to at least $150^{\circ} \mathrm{C}$. Scanning electron microscopy analysis indicated the homogeneity of the ternary composites. The maximum proton conductivity has been measured as $3.63 \times 10^{-4} \mathrm{~S} \mathrm{~cm}^{-1}$ at $150^{\circ} \mathrm{C}$.
\end{abstract}

Keywords. Sulfonated polysulfone; polyvinyl triazole; polymer electrolyte; proton conductivity; composite membrane.

\section{Introduction}

Proton-conducting polymers are attractive materials owing to their potential applications in proton exchange membrane fuel cells (PEMFCs), electrochromic devices (ECDs) and supercapacitor. $^{1-3}$ A perfluorosulfonic acid-type polymer, Nafion, is currently used as the polymer electrolyte in PEMFCs. It has hydrophilic and hydrophobic regions, and the proton transfer occurs via water molecules present in their hydrophilic channels. Several functional polymers were produced to produce alternative polymer matrices to Nafion. Among several sulfonated systems. ${ }^{4-8}$ polystyrene $^{4}$ and polysulfone ${ }^{5}$ are mostly used as homopolymer or composites. These acidic polymers have high water uptake and if used as humidified condition their usage are limited to $100^{\circ} \mathrm{C}$. Therefore alternative, materials such as benzimidazole, ${ }^{6}$ imidazole $^{7}$ and triazole ${ }^{8}$ were intercalated in these acidic polymers to provide proton conduction at high temperature. In addition, they are also blended with polyvinyl imidazole ${ }^{9}$ and polyvinyl triazole. ${ }^{10}$

Sulfonated polysulfone (SPSU) is one of the acid functional polymers that is produced with chemical sulfonation of polysulfones which are known with their high thermal, chemical and mechanical stability. ${ }^{11}$ SPSU can be used as proton conductive membrane if it is highly sulfonated and has high water uptake property. ${ }^{11,12}$ The proton conductivity

\footnotetext{
*Author for correspondence (sunugur@fatih.edu.tr)
}

of the SPSU membranes was reported as $10^{-2} \mathrm{~S} \mathrm{~cm}^{-1}$ at $80^{\circ} \mathrm{C}^{13}$ and $3.2 \times 10^{-2} \mathrm{~S} \mathrm{~cm}^{-1}$ at $90^{\circ} \mathrm{C} .{ }^{14}$ Moreover, the SPSU membranes have lower gas permeability and liquid (water and methanol) permeability than the sulfonated perfluorinated ionomers. ${ }^{15}$

Although SPSU was mostly used in humidified systems, there are studies about its usage in anhydrous membranes. For this purpose SPSU was previously doped with a heterocyclic compound, $1 \mathrm{H}$-1,2,3-benzotriazole and high proton conductivity was reported. ${ }^{16}$ In this study, SPSU was blended with polyvinyl triazole (PVTri), which has high proton transfer capability with triazole group in each repeating unit. Several composite membranes of PVTri were previously reported such as polyvinyl phosphonic acid ${ }^{17}$ and polystyrene sulfonic acid. ${ }^{18}$ The proton conductivity of these composite membranes were analysed both in humidified and anhydrous states. ${ }^{17,18}$

In our work, the SPSU was synthesized with high degree of sulfonation using trimethylsilylchlorosulfonate (TMSCS) as sulfonating agent. The proton conductive membranes were prepared by blending SPSU, polyvinyl triazole and phosphoric acid (PA) at several molar ratios. Homogeneous and free standing membranes were obtained and characterized with Fourier transform infrared spectroscopy (FT-IR), thermogravimetric analysis (TGA), differential scanning calorimeter (DSC) and scanning electron microscopy (SEM). The effect of polyvinyl triazole and phosphoric acid on proton conductivity was investigated with impedance analyzer. 


\section{Experimental}

\subsection{Materials and preparation}

The commercial polysulfone (PSU; Aldrich), TMSCS; (Aldrich), 1,2-dichloroethane (DCE; Merck), methanol (Sigma-Aldrich), dimethylformamide (DMF; Merck), 1vinyl-1,2,4-triazole (>97\%, Fluka), orthophosphoric acid (>99\%, Merck) and toluene (>99\%, Merck) were used as received. Azobisisobutyronitrile (AIBN; Merck) was recrystallized from THF prior to use. Poly(1-vinyl-1,2,4-triazole) (figure 1) was produced by free radical polymerization of 1vinyl-1,2,4-triazole in toluene using AIBN (1 mol\%) as initiator. The reaction mixture was purged with nitrogen and the polymerization reaction was performed at $85^{\circ} \mathrm{C}$ for $2 \mathrm{~h}$. The resulting polymer was precipitated as white powder and filtered and washed several times with toluene. PVTri was dried in vacuum and stored in the glove box. SPSU (figure 1) was prepared according to the literature. ${ }^{12}$ The commercial polysulfone $(0.1 \mathrm{~mol})$ was dissolved in 1,2-dichloroethane at $25^{\circ} \mathrm{C}$ for $4 \mathrm{~h}$ under nitrogen atmosphere. Trimethylsilylchlorosulfonate $(0.15 \mathrm{~mol})$ was added at room temperature as the sulfonation agent. During the reaction, $\mathrm{N}_{2}$ was purged continuously through the reaction solution and $\mathrm{HCl}$ was continuously produced and released out of the reactor with $\mathrm{N}_{2}$. After about $36 \mathrm{~h}$, methanol was added to quench the reaction, and to cleave the silyl sulfonate moieties yielding SPSU. Silicon-containing compounds, methyl sulfate, dichloroethane, methanol and water were removed through evaporation first at 1 atm and then vacuum $(400 \mathrm{mmHg})$ at the temperature of $55^{\circ} \mathrm{C} .{ }^{16}$ The resulting SPSU is soluble in methanol and DMF.

Ion exchange capacity (IEC) of SPSU was determined by volumetric titration according to literature. ${ }^{19}$ The sample was immersed and stirred in $20 \mathrm{ml}$ of $0.10 \mathrm{M} \mathrm{NaOH} / 1.0 \mathrm{M} \mathrm{NaCl}$ mixed aqueous solution ( $1 / 4$ by volume) for $24 \mathrm{~h}$ at room temperature. Subsequently, $10 \mathrm{ml}$ of $0.10 \mathrm{~N} \mathrm{HCl}$ solution was added, and the excess amount of $\mathrm{HCl}$ was back titrated with $0.025 \mathrm{~N} \mathrm{NaOH}$ aqueous solution in the presence of phenolphthalein indicator. The IEC value $\left(\mathrm{mmol} \mathrm{g}^{-1}\right)$ of the samples was calculated using

$$
\mathrm{IEC}=0.025 \times\left(V_{\mathrm{NaOH}}-V_{\mathrm{B}}\right) / W_{\mathrm{dry}}
$$

where $V_{\mathrm{NaOH}}$ is the volume of $0.025 \mathrm{~N} \mathrm{NaOH}$ aqueous solutions for the volumetric titration, $V_{\mathrm{B}}$ the volume of the $\mathrm{NaOH}$ aqueous solution for blank titration, and $W_{\text {dry }}$ the dry weight of the samples. ${ }^{19}$

Using this method the IEC value of SPSU was determined as $3.05 \mathrm{mmol} \mathrm{g}^{-1}$, which indicates that the degree of sulfonation (DS) is about $140 \%\left[\left(\mathrm{~mol} \mathrm{SO}_{3} \mathrm{H} /\right.\right.$ repeat unit) $\times 100]$.

Proton conductive composite membranes were prepared by blending of SPSU with polyvinyl triazole and $\mathrm{H}_{3} \mathrm{PO}_{4}$. A stoichiometric amount of SPSU, PVTri and $\mathrm{H}_{3} \mathrm{PO}_{4}$ were admixed in DMF with several mol ratios $(X=$ $0.5,1,2$ and 4 ) for $5 \mathrm{~h}$ at $50^{\circ} \mathrm{C}$. The membrane was then prepared by casting of the solutions on a polished poly(tetrafluoroethylene), and the solvent was slowly evaporated at $50^{\circ} \mathrm{C}$ for $24 \mathrm{~h}$. To ensure complete solvent removal, the membranes were placed under vacuum $200 \mathrm{mmHg}$ at $50^{\circ} \mathrm{C}$. Homogeneous and free standing membranes were obtained.

\subsection{Characterizations}

FT-IR spectra were recorded on a Bruker a-P in ATR in range of $4000-400 \mathrm{~cm}^{-1}$.

Thermal stabilities of the polymer electrolytes were examined by TG analyses with a Perkin-Elmer STA 6000. The samples $(\sim 10 \mathrm{mg})$ were heated from room temperature to $700^{\circ} \mathrm{C}$ under $\mathrm{N}_{2}$ atmosphere at a scanning rate of $10^{\circ} \mathrm{C}$ $\min ^{-1}$.

DSC measurements were carried out on a Perkin-Elmer JADE DSC under nitrogen atmosphere and heating-cooling curves were recorded at a rate of $10^{\circ} \mathrm{C} \mathrm{min}^{-1}$.

The proton conductivity studies of the samples were performed using a Novocontrol dielectric-impedance analyzer. The films were sandwiched between platinum blocking electrodes and the conductivities were measured in the frequency range $1 \mathrm{~Hz}-3 \mathrm{MHz}$ at $10^{\circ} \mathrm{C}$ intervals. The temperature was controlled with a Novocontrol cryosystem, which is applicable between -100 and $250^{\circ} \mathrm{C}$.

The morphology of the membranes was observed by SEM type JEOL 7001 FESEM. The samples were previously coated with gold in a sputtering device.

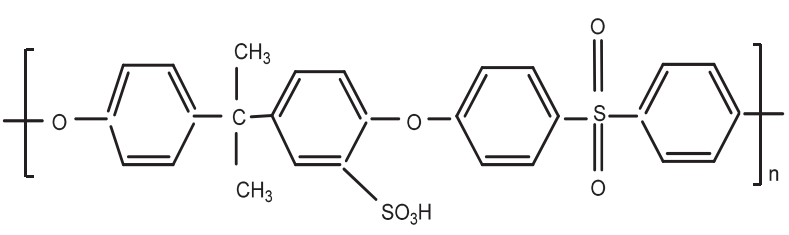

(a)

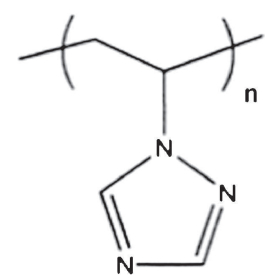

(b)

Figure 1. Molecular structures of (a) sulfonated polysulfone and (b) polyvinyltriazole. 


\section{Results and discussion}

\section{$3.1 \quad$ FT-IR studies}

Figure 2 shows the FT-IR spectra of pure polysulfone, SPSU, PVTri and SPSU-PVTri $X-P A X$ composite membranes. SPSU has peaks at 687, 1015, 1100, 1150, 1240, $1483,2970,3070$ and $3440 \mathrm{~cm}^{-1}$ that corresponds to $\mathrm{C}-\mathrm{S}$, $\mathrm{SO}_{3}, \mathrm{C}-\mathrm{O}, \mathrm{R}-\mathrm{SO}_{2}-\mathrm{R}, \mathrm{C}-\mathrm{O}, \mathrm{C}=\mathrm{C}$ (aromatic), $\mathrm{CH}$ (aliphatic), $\mathrm{CH}$ (aromatic) and $\mathrm{OH}$ stretching bonds, respectively. ${ }^{20-22}$ When compared with FT-IR of PSU, the presence of -OH peaks at $3500 \mathrm{~cm}^{-1}$ symmetric and asymmetric vibrations of $\mathrm{SO}_{3} \mathrm{H}$ groups at 1156 and $1302 \mathrm{~cm}^{-1}$ and also $\mathrm{O}=\mathrm{S}=\mathrm{O}$ stretching vibration of $-\mathrm{SO}_{3}$ groups near $1015 \mathrm{~cm}^{-1}$ in FTIR of SPSU confirm the sulfonation of PSU ${ }^{23}$ PVTri has C$\mathrm{N}$ and $\mathrm{C}=\mathrm{N}$ stretchings at $1430-1650 \mathrm{~cm}^{-1}$ range and $\mathrm{N}-\mathrm{N}$ stretching at $1270 \mathrm{~cm}^{-1} .{ }^{24}$ In the ternary composites there is a bond at $1665 \mathrm{~cm}^{-1}$ due to $\mathrm{N}-\mathrm{H}$ bending vibration of acidprotonated triazole rings. Between 3500 and 2000 a broadening of the band can be related to hydrogen bonding network formation. Within $1800-900 \mathrm{~cm}^{-1}$ region, the peaks near 1100 and $975 \mathrm{~cm}^{-1}$ are attributed to characteristic absorptions of $\mathrm{HPO}_{4}^{2-}$ and $\mathrm{H}_{2} \mathrm{PO}_{4}^{-}$in the blends and they increase with PA content. ${ }^{25}$

\subsection{Thermal analysis}

Figure 3 shows the thermogravimetric analysis of PSU, SPSU, PVTri and SPSU-PVTri $X-P A X$ composites. Pure $\mathrm{PSU}$ is thermally stable up to $500^{\circ} \mathrm{C}$ and then major weight loss occurs due to degradation of the polymeric backbone. ${ }^{14}$ The TGA curve of SPSU has two weight loss region, where $30 \%$ weight loss occurs between 200 and $350^{\circ} \mathrm{C}$ due to degradation of sulfonic acid groups and the degradation of polymer backbone occurs above $500^{\circ} \mathrm{C} .^{22,26}$ This distinct change in TGA curve also verifies the sulfonation of PSU. PVTri homopolymer is thermally stable up to $350^{\circ} \mathrm{C}$ and the major weight loss derives from the

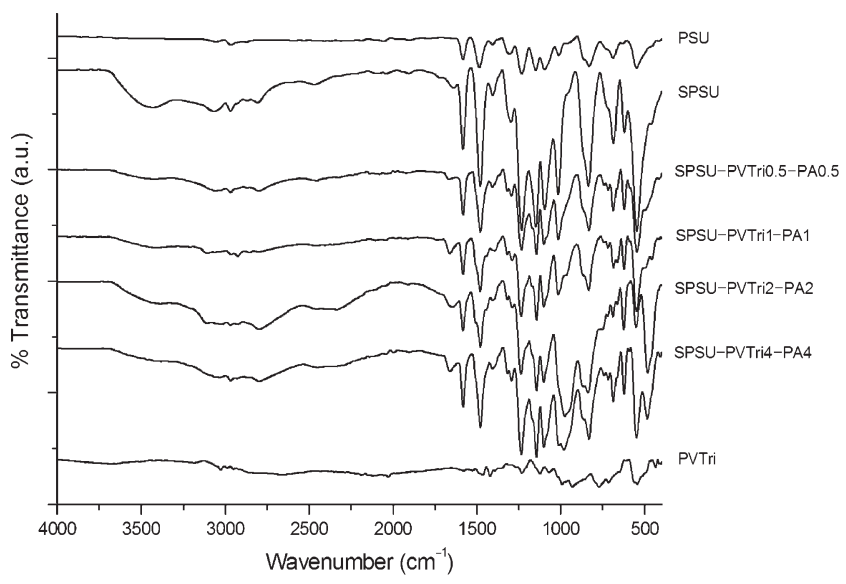

Figure 2. FT-IR spectra of PSU, SPSU, PVTri and SPSUPVTri $X$-PA $X(X=0.5,1,2,4)$ membranes. thermal decomposition of the side groups and polymer main chain. The minor $(10 \%)$ weight loss up to $200^{\circ} \mathrm{C}$ may be attributed to the absorbed humidity. The ternary composites can be said to be thermally stable up to at least $150^{\circ} \mathrm{C}$ and decomposition temperature decreases with $\mathrm{H}_{3} \mathrm{PO}_{4}$ content as expected.

DSC curves of SPSU and SPSU-PVTri $X-P A X$ are given in figure 4. Pure PSU and PVTri are reported to have $T_{\mathrm{g}}$ of 185 and $165^{\circ} \mathrm{C}$, respectively. ${ }^{16,24}$ After sulfonation the $T_{\mathrm{g}}$ decreased to $120^{\circ} \mathrm{C}$. SPSU-PVTri $X-\mathrm{PA} X$ blends showed glass transition $\left(T_{\mathrm{g}}\right)$ temperatures of $115,108,100$ and $97^{\circ} \mathrm{C}$ for $X=0.5,1,2,4$, respectively. The ternary blends have $T_{\mathrm{g}}$ values lower than pure PVTri and SPSU, which is due to plasticizing effect of PA.

\subsection{Morphology}

The morphology study is important to confirm the homogeneity of polymer-polymer blends. In this work, SPSUPVTri $X-P A X$ membranes are observed to be more homogeneous compared to SPSU-PVTri blends. Figure 5 shows SEM of the ternary composites. The membranes exhibit single-phase formation, which shows that the PVTri and $\mathrm{H}_{3} \mathrm{PO}_{4}$ uniformly distributed into the polysulfone matrix and there is no agglomeration or phase separation at micrometre and nanometre scale level. In figure $5 d$ we observe many cracks in $\mathrm{nm}$ scale, which is related with the drying procedure and has no effect on the proton conductivity or thermal properties.

\subsection{Conductivity measurement}

The frequency-dependent $\mathrm{AC}$ conductivities, $\sigma_{\mathrm{AC}}(\omega)$ of the polymer electrolyte membranes were calculated at different temperatures using

$$
\sigma^{\prime}(\omega)=\sigma_{\mathrm{AC}}(\omega)=\varepsilon^{\prime \prime}(\omega) \omega \varepsilon_{0},
$$

where $\sigma^{\prime}(\omega)$ is the real part of conductivity, $\omega=2 \pi f$ the angular frequency, $\varepsilon_{\mathrm{o}}$ the vacuum permittivity $\left(\varepsilon_{\mathrm{o}}=\right.$ $\left.8.852 \times 10^{-14} \mathrm{~F} \mathrm{~cm}^{-1}\right)$, and $\varepsilon^{\prime \prime}$ the imaginary part of complex dielectric permittivity $\left(\varepsilon^{*}\right)$. The proton conductivities of anhydrous polymer electrolytes were measured from 20 to $150^{\circ} \mathrm{C}$.

Figure 6 shows the AC conductivity of SPSU-PVTri4PA4 vs. log frequency at several temperatures. The conductivity increases with the temperature and the DC conductivity $\left(\sigma_{\mathrm{DC}}\right)$ of the samples was derived from the plateaus of $\sigma_{\mathrm{AC}} v s . \log$ frequency by linear fitting of the data. The DC conductivities of SPSU-PVTri $X$ and SPSU-PVTri $X-P A X$ are compared in figure 7 . It is clear that the DC conductivity strongly depends on the temperature, PVTri and $\mathrm{H}_{3} \mathrm{PO}_{4}$ ratio. The maximum proton conductivity was obtained as $2.5 \times 10^{-4}$ and $2.3 \times 10^{-4} \mathrm{~S} \mathrm{~cm}^{-1}$ for SPSU-PVTri4-PA4 and SPSU-PVTri2-PA2, respectively, at $150^{\circ} \mathrm{C}$.

As SPSU has high thermal stability, good mechanical and film forming property, it was studied by different groups 


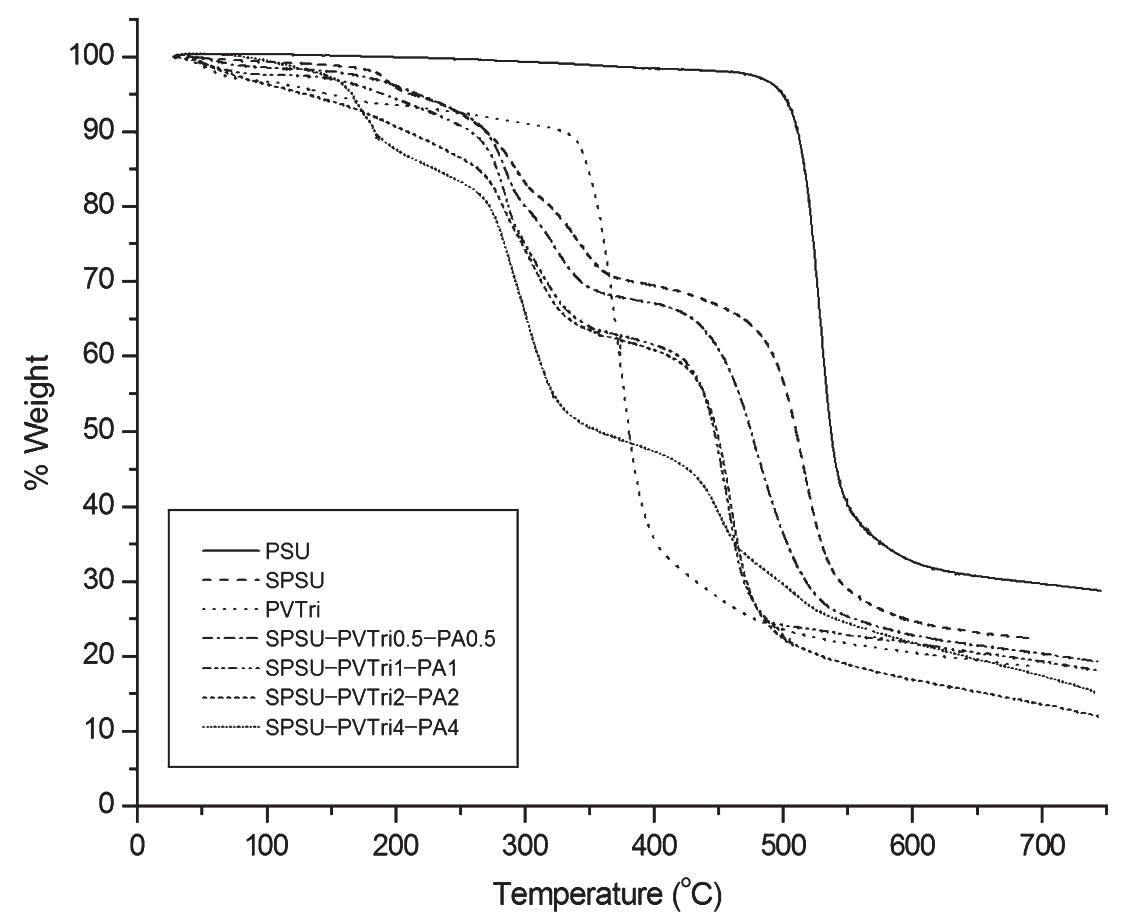

Figure 3. TGA curves of PSU, SPSU, PVTri and SPSU-PVTri $X-P A X(X=0.5,1$, $2,4)$ electrolytes at a heating rate of $10^{\circ} \mathrm{C} \mathrm{min}^{-1}$.

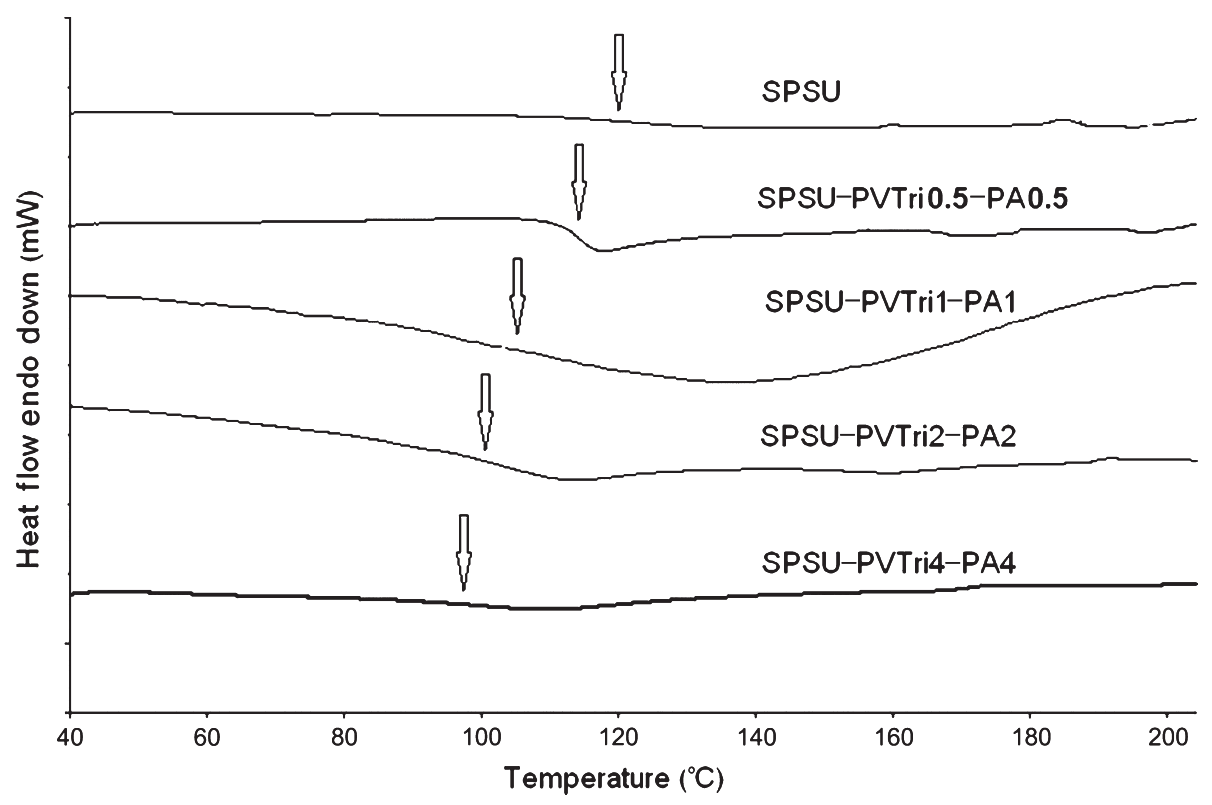

Figure 4. DSC curves of SPSU and SPSU-PVTri $X-\mathrm{PA} X(X=0.5,1,2,4)$ electrolytes at a heating rate of $10^{\circ} \mathrm{C} \mathrm{min}^{-1}$.

as proton conductive material but most of them are in humidified condition. ${ }^{12,22}$ SPSU/1 $H$-1,2,3-triazole composite membranes were reported as anhydrous system, but the system produced considerable proton conductivity at very high dopant ratios. ${ }^{27}$ Manthiram and co-workers immobilized 5-aminobenzotriazole to polysulfone and after blending with sulfonated poly(ether ether ketone) they investigated the proton conductivity and obtained values around $10^{-4} \mathrm{~S} \mathrm{~cm}^{-1}$ in anhydrous conditions. ${ }^{28,29}$ In another study, phosphatoantimonic acid was intercalated into SPSU and after humidification they investigated the proton conductivity. ${ }^{30}$ Previously we studied SPSU/benzotriazole system, which resulted in high proton conductivity at lower dopant ratios. ${ }^{16}$ In order to be used in anhydrous conditions, SPSU may be blended with 
(a)

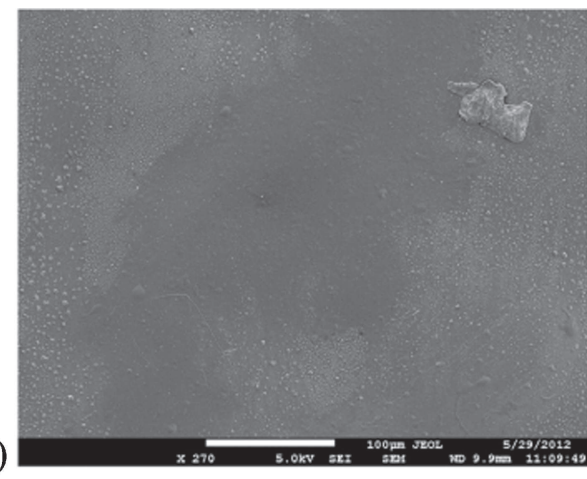

(c)

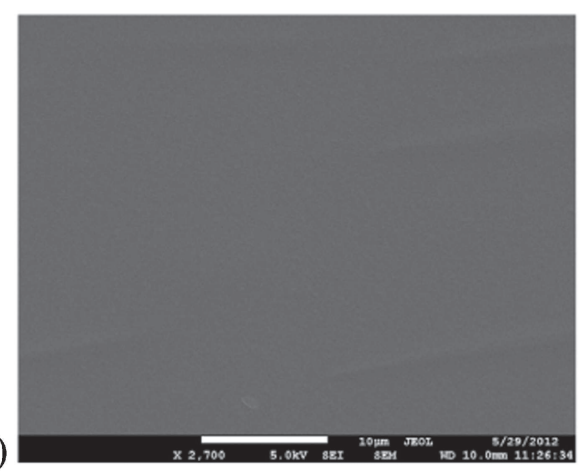

(b)

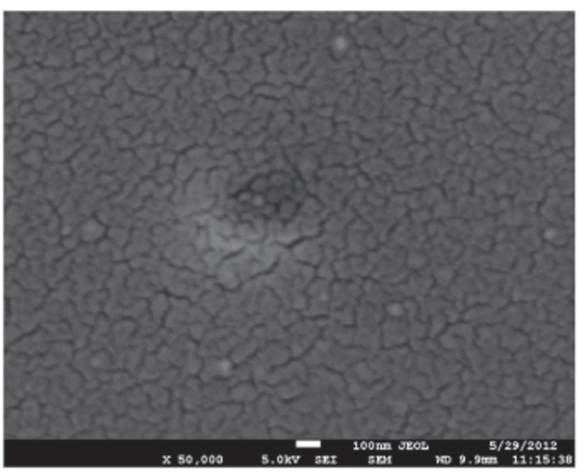

(d)

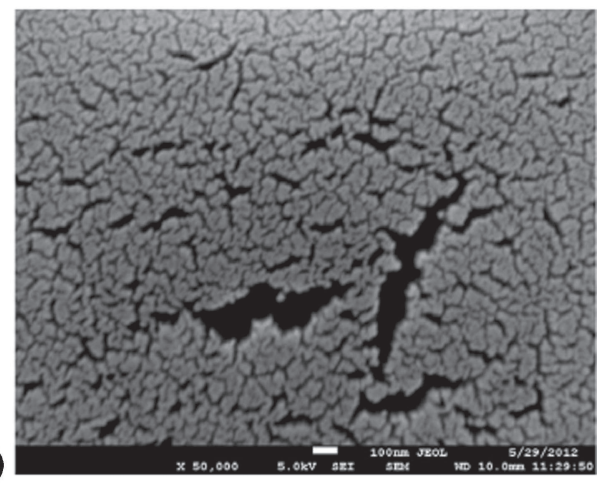

Figure 5. SEM images of (a and b) SPSU-PVTri1-PA1 and (c and d) SPSU-PVTri2-PA2 membranes.

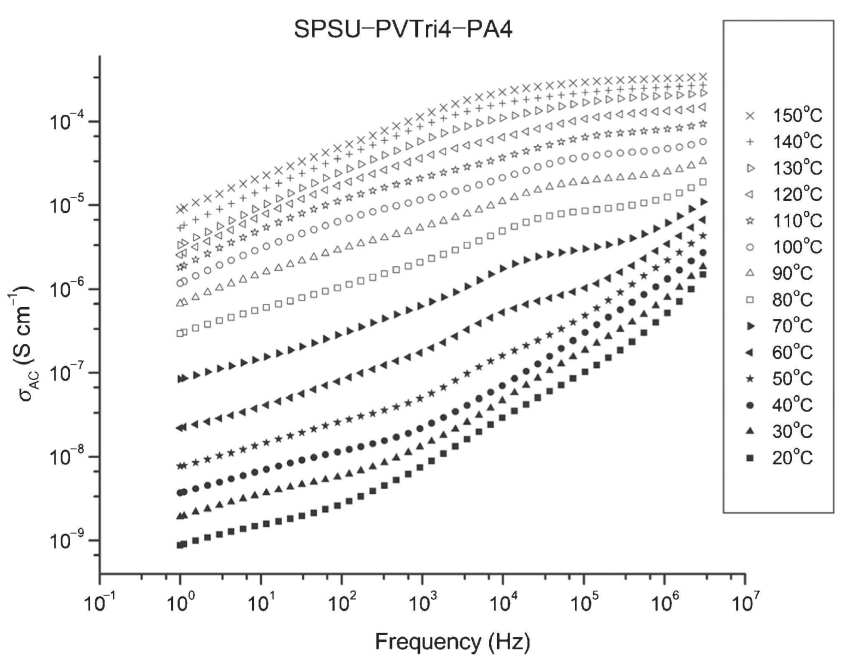

Figure 6. AC conductivity of SPSU-PVTri4-PA4 vs. log frequency $(\mathrm{Hz})$ at various temperatures.

azole-containing polymer and the resulting channel between polymers may be filled with high proton conductive solvent such as PA.

In this work polysulfone was sulfonated with high ratio $(140 \%)$ and blended with polyvinyl triazole. Here polyvinyl triazole is considered to make ionic interaction with sulfonic acid units of SPSU. The binary mixtures resulted in less homogeneous membrane and also low proton conductivity, which may be due to ionic crosslink that limit the proton

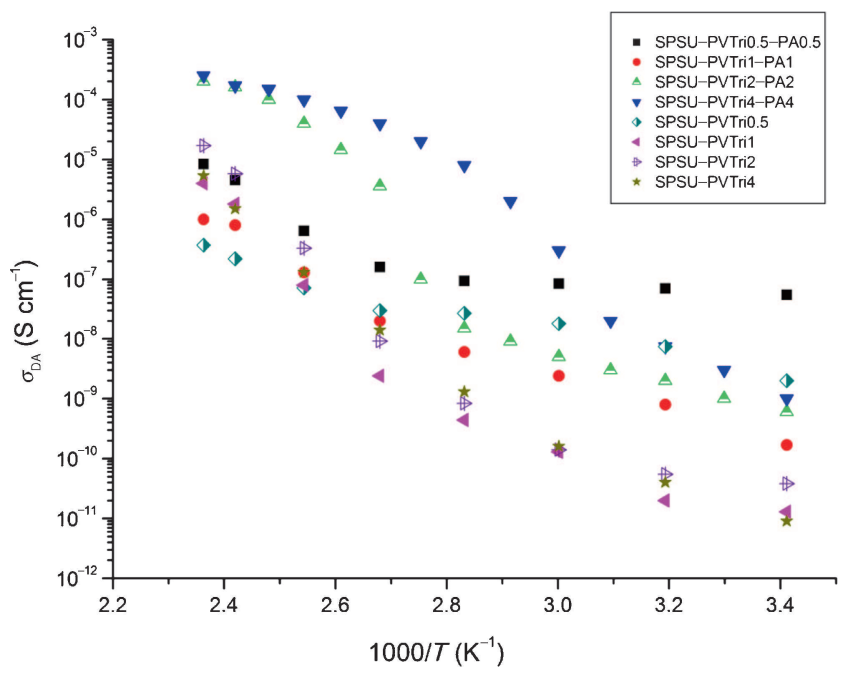

Figure 7. DC conductivities of SPSU-PVTriX and SPSUPVTri $X-\mathrm{PA} X(X=0.5,1,2,4)$ as a function of reciprocal temperature.

transfer in the matrix.6,18 Therefore, ternary membranes were prepared by homogeneous solution doping of SPSU/ PVTri with $\mathrm{H}_{3} \mathrm{PO}_{4}$. Here homogeneous membranes were obtained and proton conductivity increased to $2.5 \times$ $10^{-4} \mathrm{~S} \mathrm{~cm}^{-1}$ at $150^{\circ} \mathrm{C}$ for SPSU-PVTri4-PA4. For this ternary composite the proton transfer path can be explained as Grotthuss mechanism, where sulfonic acid and PA groups protonates free nitrogens in PVTri and proton transfer occurs between protonated and non-protonated 
nitrogens in heterocyclic group and also sulfonate and phosphate groups. ${ }^{2}$ At higher doping ratios, the DC conductivity curves show VTF (Vogel-Tamman-Fulcher) behaviour, which indicates the contribution of segmental motions on the proton conductivity in these novel matrices.

\section{Conclusions}

In the present work, SPSU was produced with high sulfonation ratio using trimethylsilylchlorosulfonate as sulfonating agent. Both direct titration and ion exchange capacity measurements indicated a degree of sulfonation of $140 \%$. The polymer electrolyte membranes were prepared by blending of SPSU with polyvinyl triazole and PA. The ionic interaction between acidic groups and polyvinyl triazole was proved by FT-IR spectroscopy. Thermogravimetric analysis showed that the materials are thermally stable up to at least $150^{\circ} \mathrm{C}$. The proton conductivity of these materials increased with the increase in polyvinyl triazole and PA contents. The maximum proton conductivity was measured for SPSU-PVTri4-PA4 as $2.5 \times 10^{-4} \mathrm{~S} \mathrm{~cm}^{-1}$ at $150^{\circ} \mathrm{C}$ in anhydrous condition. In that matrix the presence of PA provided homogeneity and also form a proton transfer path inside the polymer matrix. The material can be used as membrane in high-temperature PEMFC applications.

\section{References}

1. Daletou M K, Gourdoupi N and Kallitsis J K 2005 J. Membr. Sci. 252115

2. Celik S Ü, Bozkurt A and Hosseini S S 2012 Prog. Polym. Sci. 371265

3. He R H, Li Q F, Bach A, Jensen J Q and Bjerrum N J 2006 J. Membr. Sci. 27738

4. Göktepe F, Bozkurt A and Günday S T 2008 Polym. Int. 57133

5. Lufrano F, Squadrito G, Patti A and Passalacqua E $2000 \mathrm{~J}$. Appl. Polym. Sci. 771250

6. Kim J D, Mori T, Hayashi S and Honma I 2007 J. Electrochem. Soc. 154 A290

7. Yamada M and Honma I 2005 Polymer 462986
8. Günday S T, Bozkurt A, Meyer W H and Wegner G $2006 \mathrm{~J}$. Polym. Sci. Part B: Polym. Phys. 443315

9. Pu H, Meyer W H and Wegner G 2001 Macromol. Chem. Phys. 2021478

10. Sen U, Bozkurt A and Ata A 2010 J. Power Sources 195 7720

11. Furtado Filho A A M and Gomes Ailton de 2010 Int. J. Polym. Mater. 59424

12. Chen S L, Bocarsly A B and Benziger J 2005 J. Power Sources 15227

13. Lufrano F, Gatto I, Staiti P, Antonucci V and Passalacqua E 2001 Solid State Ionics 14547

14. Lufrano F, Baglio V, Staiti P, Arico A S and Antonucci V 2008 J. Power Sources 17934

15. Lufrano F, Baglio V and Staiti P 2006 Desalination 199283

16. Gustian I, Celik S U and Bozkurt A 2012 J. Mater. Res. 27 2650

17. Aslan A and Bozkurt A 2009 J. Power Sources 191442

18. Aslan A, Sen U and Bozkurt A 2009 J. Electrochem. Soc. 156 B1112

19. Kim S H, Park Y C, Jung G H and Cho C G 2007 Macromol. Res. 15587

20. Rama C, Escobar I and Long X 2006 Desalination 188203

21. Coates J 2000 Encyclopedia of analytical chemistry (Chichester: John Wiley \& Sons Ltd) p 10815

22. Smitha B, Anjali Devi D and Sridhar S 2008 Int. J. Hydrogen Energy 334138

23. Zhou W, Xiao J, Chen Y, Zeng R, Xiao S, Nie H, Li F and Song C 2011 Polym. Adv. Technol. 221747

24. Celik S Ü, Aslan A and Bozkurt A 2008 Solid State Ionics 179 683

25. Bouchet R and Siebert E 1999 Solid State Ionics 118287

26. Park H B, Shin H-S, Leea Y M and Rhim J-W 2005 J. Membr. Sci. 247103

27. Li S, Zhou Z, Zhang Y and Liu M 2005 Chem. Mater. 175884

28. Li W, Manthiram A, Guiver M D and Liu B 2010 Electrochem. Commun. 12607

29. Fu Y, Manthiram A and Guiver M D 2006 Electrochem. Commun. 81386

30. Genova-Dimitrova P, Baradie B, Foscallo D, Poinsignon C and Sanchez J Y 2001 J. Membr. Sci. 18559 